\title{
Conference Review Emotions in Motion: The Passions of Tourism, Travel and Movement
}

(Leeds Metropolitan University, 4-7 July, 2009)

Travel and tourism set bodies in motion, fostering often intense interactions with the uncommon, the extra-ordinary, and the exotic. In so doing, one's senses are stirred, passions are stoked, and highly charged emotional experiences are created. Pilgrims at sacred centers tearfully encounter spiritual realms, often through painful, collective penitential acts of mortification or self-sacrifice. Explorers are exposed to strange sensations, to unfamiliar heat or cold, tastes or smells, colors or forms that contrast with the aesthetics of their quotidian environment. Even pleasure-seekers who temporarily leave the security of their daily life to experience the unusual in secure doses are plunged into almost ritual liquidification of social norms and moral rules that frame their daily life. Yet perhaps because of its variability and subjectivity-and its complex moral, social, political, religious and economic implications - the role of emotion in tourism has rarely been the focal point of a major international conference until the summer of 2009, when scholars from the social sciences, humanities, economics and professional fields convened in Leeds, United Kingdom to directly address this topic.

Held in conjunction with the Royal Anthropological Institute of Great Britain and Ireland's Eleventh Annual International Festival of Ethnographic Film, Emotions in Motion: The Passions of Tourism, Travel and Movement was organized by the Centre for Tourism and Cultural Change at Leeds Metropolitan University. This was the seventh in a series of annual conferences sponsored by the Centre, and, arguably, the most complex to date. As in the past, it brought together roughly 100 scholars from North America, Europe, Africa, and Asia who presented varied research on themes such as romance and eroticism, shamanism and sublimation, gas- 


\section{Emotions in Motion}

tronomy and dance, literary travel and adventure tourism. Through these papers, three main themes were addressed.

The first focused on the social and historical formation of cognition in tourism. Within this theme, a range of papers dealt with the existential challenges many tourists face when confronting the a priori instability of the touristic ground. Opening the conference, Elvi Whittaker explored the historical contexts of nineteenth-century romanticist movements in Europe and North America that framed the quest for "peak experiences" by Western tourists. Coupling bio-neurological theory with anthropological concepts concerning the culturally constructed nature of the sensate body, Whittaker analyzed different "emotionally charged" and "unmistakably transformative" moments of the journey-encounters with specific landscapes, urban architectures and arts-which trigger tourists to reflect on their relationship with the greater world and reconstitute them as social beings.

Different topical papers discussed tourism's existential dimension in specific contexts. Some outlined the allegorical nature of symbolic worlds to constitute and legitimate social life, while others examined the emotions generated by the tourist's movement through such worlds; the latter considered emotions as theoretical cues to understand the transformative power of tourism. Papers focusing on religious tourists revealed how travelers invoke these forces to create meaning out of life and death, such as Michael Di Giovine's examination of pilgrim typologies at the Catholic shrine of St. Padre Pio of Pietrelcina, and Samuel Anderson's ethnographic video of Ouidah's National Vodun Day festival in Benin. Jill Steward's talk on spa tourism reminded listeners that such sites of transcendence-religious or secularare nevertheless embodied. Indeed, papers addressing "battlefield tourism," Iranian martyrdom, and visits to former concentration camps revealed that touristic engagements often blur the boundaries between life and death, thus challenging tourists to contemplate their bodies not only as vehicles that move through life, but also as actors that participate in-and impact-society. Taking a theme reminiscent of Jonathan Parry's Death in Banaras (1995) and Christopher Justice's Dying the Good Death: The Pilgrimage to Die in India's Holy City (1997)—classic ethnographies of mortuary ghats in India's sacred city of Varanasi-Angelina Karpovich provided an extreme illustration of this phenomenon. She argued that, in certain circumstances, the instability of the touristic ground becomes a setting of no return, a passage to another world achieved through suicide while on holiday. 
In their plenary addresses, both Nelson Graburn and Tim Edensor illustrated how peak experiences are framed and embedded within a particular cultural history. The existential challenge of Japanese tourism, Graburn argued, lies in the defiance of the very nature of being, challenging tourists to reappropriate the body and to contemplate the symbolic separations among time, belonging and social existence. Drawing on Henry Lefebvre's Eléments de rythmanalyse (1992), Edensor investigated concepts of "mobile" and "embodied" rhythm through which tourism resembles aspects of the everyday.

Engaging in tourism research is, in many ways, a phenomenological process of engaging in Otherness and Otherworldliness, thrusting several presenters into self-reflexivity. Although this topic is not uncommon in the post-modern literature, Pamila Gupta's beautifully written paper and Desmond Wee's engaging photo essay were particularly evocative contributions, sparking a productive debate on the epistemic underpinning of modernist thinking and of modern scientific methodologies.

These explorations of the allegorical quality of Others introduced a second theme of the conference. As historically constituted modes of perception through which tourists impose order on the world, tourism can provide a general way to think and organize social relationships. A variety of presentations, including those by Veronica Davidov and Joseph Ploner, studied how visitors use touristic processes to project themselves into wider realms of intergroup relationships where some people are celebrated, and often celebrate themselves, as being more emotional, more authentic, more beautiful, or more sociable than others. They revealed that spatial realms, gender, politics, and social events are often emotionally codified as spaces for "self-fashioning," as Stephen Greenblatt dubbed it (Renaissance Self-Fashioning: from More to Shakespeare, 1980). Emotion—or being emotional, or being able to trigger certain emotions-often seems to become here a social signifier, a distinguishing feature in what Johannes Fabian had called a "theater of memory" (Time and the Other: How Anthropology Makes Its Object, 1983), where different spaces or actors are made to play specific roles within a global narrative of human evolution.

Moving into more ethnographically grounded explorations of the practice of tourism, the third theme addressed the varied ways these cultural “contact zones” (Mary Louise Pratt, Imperial Eyes: Travel Writing and Transculturation, 1992) receive or cater to touristic strangers. Papers by Tamas 


\section{Emotions in Motion}

Regi, Melody Cox, Valerio Simoni, and Anne-Mette Hermansen revealed the complex politics of such spheres of hospitality, and hosts' strategic use of various mediators (material culture, music, sexualized bodies) to entice tourists and to enable interchange.

Networking opportunities were also built into the conference program, although perhaps reflecting the current economic climate, expensive research trips into the field and gala dinners were eschewed for more informal gatherings in local pubs and restaurants. Of particular note was a forum held for young scholars-those who were currently pursuing, or who have recently completed, their doctorates. The nearly fifty participants in attendance candidly exchanged their own personal experiences concerning the benefits and challenges of pursuing dedicated tourism research, the availability of tenure-track positions in the current economic crisis, and suggestions for further professionalization. The Centre has held this type of forum in the past, but this year's group seemed to be more proactive, agreeing on the need for ongoing dialogue in the field. They partnered with the seasoned scholars to produce a resolution formalizing an international tourism research network that would not only distribute information on upcoming conferences, but would create an online community. In September 2009, a group called Tourism-Contact-Culture Research Network was created (www.tourismcontactculture.org.uk). Besides its initial goal of sharing information about tourism research, this network has initiated an annual conference series with a first event held in Lisbon, Portugal, 9-12 September 2010. A testament to the network's initial success, as well as the compelling nature of the theme of emotions in tourism, roughly two hundred researchers presented high-quality papers on the theme of Tourism and the Seductions of Difference at this meeting. This is an important, if basic, step in the right direction, particularly given the multidisciplinary and global nature of the present scholarship.

Michael A. Di Giovine Department of Anthropology

University of Chicago

and

David Picard

CRIA/FCSH-UNL

Universidade Nova de Lisboa, Portugal 